\title{
Thermal properties variations in unconsolidated material for very shallow geothermal application (ITER project)**
}

\author{
Eloisa Di Sipio* and David Bertermann \\ Department of Geology, GeoZentrum Nordbayern, Friedrich-Alexander University Erlangen-Nuremberg, Schlossgarten 5, \\ 91054, Erlangen, Germany
}

Received August 2, 2017; accepted December 16, 2017

\begin{abstract}
In engineering, agricultural and meteorological project design, sediment thermal properties are highly important parameters, and thermal conductivity plays a fundamental role when dimensioning ground heat exchangers, especially in very shallow geothermal systems. Herein, the first $2 \mathrm{~m}$ of depth from surface is of critical importance. However, the heat transfer determination in unconsolidated material is difficult to estimate, as it depends on several factors, including particle size, bulk density, water content, mineralogy composition and ground temperature. The performance of a very shallow geothermal system, as a horizontal collector or heat basket, is strongly correlated to the type of sediment at disposal and rapidly decreases in the case of dry-unsaturated conditions. The available experimental data are often scattered, incomplete and do not fully support thermo-active ground structure modeling. The ITER project, funded by the European Union, contributes to a better knowledge of the relationship between thermal conductivity and water content, required for understanding the very shallow geothermal systems behaviour in saturated and unsaturated conditions. So as to enhance the performance of horizontal geothermal heat exchangers, thermally enhanced backfilling material were tested in the laboratory, and an overview of physical-thermal properties variations under several moisture and load conditions for different mixtures of natural material was here presented.

Keywords: soil, very shallow geothermal systems, thermal conductivity, water content, thermally enhanced backfilling
\end{abstract} material

\section{INTRODUCTION}

Nowadays, knowledge of soil thermal properties becomes increasingly important in many areas of engineering and environmental applications, as well as in meteo-

\footnotetext{
*Corresponding author e-mail: eloisa.di.sipio@fau.de

**This work was supported by the European Union. ITER project (http://iter-geo.eu/) has received funding from the European Union's Framework Programme for Research and Innovation Horizon 2020 under the Marie Skłodowska-Curie Grant Agreement No. [661396-ITER], (2014-2020).
}

rology, agronomy and soil science (Abu-Hamdeh, 2000; Alritmi et al., 2016; Nikolaev et al., 2013). The performance of several engineering projects as heat exchange systems, energy piles and ground thermal storage or facilities, such as for high voltage power cabling, nuclear waste depository and pipeline routing, to name but few, depends strongly on the ability of soil to conduct heat (Tarnawski et al., 2013; Zhang et al., 2017).The term 'soil' has different meanings according to different scientific fields. In agricultural and soil sciences, it usually refers to the upper weathering underground layer, which is a mixture of organic matter, minerals, gases, liquids and organisms that, together, support life, and are formed by weathering (Chesworth, 2008). Discussion on the use (and sometime the over-use) of soil requires a careful management, since this very tiny superficial layer is not renewable in short time (Amundson et al., 2015).

In geology, this term stands for the accumulation of disintegrated rock material, found in place or relocated, that came about due to the weathering processes and involves depth greater than $1 \mathrm{~m}$ below the ground surface. Usually, it refers to any loose material below the plant growth zone, defined also as sediment and / or unconsolidated material (Venkatramaiah, 2014).

In geotechnical engineering, soil is the loose inorganic material produced by the disintegration of rocks, and which is employed mainly as construction or foundation material. Soil mechanics is interested in the behaviour of soil under the application of load (i.e. foundations) and classifies it according to particle size, distribution and plasticity of the material (Terzaghi and Peck, 1948; Venkatramaiah, 2014).

(C) 2018 Institute of Agrophysics, Polish Academy of Sciences 
Furthermore, according to the United States Department of Agriculture (USDA, 2012), soil is defined as an unconsolidated, un-indurated, or slightly-indurated, loosely compacted products of the disintegration and decomposition processes of weathering, and it is classified according to its engineering properties.

In this paper, the term 'soil' is used mainly in its geological and engineering acceptance, as also usually reported in the scientific literature devoted to the thermal properties study of unconsolidated material (Abu-Hamdeh et al., 2003; De Vries, 1963; Farouki, 1981; Nikolaev et al., 2013; Zhang et al., 2017).

In detail, the thermal conductivity $(\lambda)$ plays a fundamental role when dimensioning ground heat exchangers, especially very shallow geothermal (VSG) systems. Here, the most interesting are the first $2 \mathrm{~m}$ of depth from the ground level (Di Sipio and Bertermann, 2017a). In fact, since 1980, soils have been studied and used also as heat reservoirs in geothermal applications, either as a heat source (in winter) or sink (in summer) coupled mainly with heat pumps (Ochsner et al., 2001; Chong et al., 2013). Soils are also a natural and valid renewable alternative for thermal energy supply for heating/cooling residential and tertiary buildings and agricultural greenhouses.

The performance of a VSG system as horizontal collectors or special forms is strongly correlated to the kind of grain size condition at disposal. Performance also rapidly decreases in case of dry-unsaturated conditions in the surrounding soil. For example, the coefficient of performance (COP), a technical parameter measuring the heat pump efficiency, suddenly decreases when the soil is dry and improves when an increase of the water content is noticed (Drefke et al., 2017; Farouki, 1981; Leong et al., 1998; Wu et al., 2015).

Furthermore, in the first meters of depth below the ground surface, when groundwater flow is not present, conduction is the dominant process governing heat transfer in soil. This process is driven by temperature gradients and depends mainly on thermal conductivity, in turn, a property strictly related to water content (Gonzales et al., 2012; Leong et al., 1998; Schön J.H., 2011; Song et al., 2014). Therefore, a better knowledge of the relationship between thermal conductivity and water content is required for understanding the VSG systems behaviour in saturated and unsaturated conditions. This constitutes the main focus of the research here presented.

Other thermal parameters are not detailed in this work, such as heat capacity and/or thermal diffusivity, defined the former as the capability of a material to store heat, the latter as the physical property governing the transient heat diffusion measuring the penetration of temperatures changes into a material (Clauser, 2011a,b; Schön, 2011). Heat capacity is very important, for example, in planning underground thermal energy storage (UTES) or final repository for spent nuclear fuel in deep bedrock, involving depth greater than those considered for VSGs systems.
Thermal diffusivity can be derived successfully knowing the thermal conductivity, specific heat capacity and density of any material (Clauser, 2011a,b; Kukkonen and Lindberg, 1998; Schön, 2011).

However, the determination of heat transfer in soils is difficult to estimate, because this depends on several factors, including, among others, grain size, bulk density, water content, mineral composition, ground temperature, porosity and organic matter (Farouki, 1981; Gonzalez et al., 2012; Hiraiwa et al., 2000; Saxton and Rawls, 2006; Schön, 2011).

In addition, the thermal properties of soil are greatly affected by temperature variations. An increase in temperature generally leads to an increase in thermal conductivity; however, when temperature decreases below the freezing point, non-conductive heat transfer mechanisms must also be taken into consideration, as the release of latent heat when the phase change between water and ice takes place, together with the different heat transfer features of frozen and unfrozen soils, is greatly influenced by the available soil moisture content (Farouki, 1981; Hinkel et al., 2001; Leong et al., 1998; Wu et al., 2015). For example, dry soils, unlike those saturated or half-saturated, do not show thermal conductivity variations with temperature (Leong et al., 1998). Moreover, repeated thermal anomalies, as freezethaw cycles induced by borehole heat exchangers (BHE), affect the hydraulic and geotechnical behaviour of sediments and grouting material near the exchangers (Anbergen et al., 2014, 2015; Dalla Santa et al., 2016).

In the framework of the ITER Project (Improving Thermal Efficiency of horizontal ground heat exchangers, $\mathrm{http} / /$ iter-geo.eu/) the interactions between soils, VSGs, environment and climate in extreme thermal situations (when the heat pump is running in heating mode for a very long time forcing the ground temperature to drop below $0^{\circ} \mathrm{C}$ ) are detailed in Di Sipio and Bertermann (2017b).

As is well known from literature, soil is a material consisting of several components (solid particles, gas and/ or liquid phase), characterised each by a typical thermal conductivity value. The range of values varies across two orders of magnitude and can be summarised as follows:

$$
\lambda_{\text {air }}<\lambda_{\text {dry-soil }}<\lambda_{\text {water }}<\lambda_{\text {saturated-soil }}<\lambda_{\text {mineral }},
$$

where: $\lambda_{\text {air }}, \lambda_{\text {water }}, \lambda_{\text {mineral }}$ were $0.026,0.56$, and $3.0 \mathrm{~W} \mathrm{~m}^{-1} \mathrm{~K}^{-1}$, respectively. This sequence highlights, on one hand, the dominant role of the solid particle as the main heat transfer path, and, on the other, the influence of water content in varying the thermal properties of the soil (Dong et al., 2015 Yun and Santamarina, 2008).

Several studies have been performed in order to identify the influence of mineralogy, grain size and gradation, stress level and water content on thermal conductivity for different kinds of soil material. Larger $\lambda$ values can be related to : (i) higher quartz content (Tarnawski et al., 2002, 2009), 
(ii) the presence of small particles able to fill the voids (Tien et al., 2010) or (iii) higher bulk density (Choo et al., 2013), (iv) the amount of water that can improve consistently the thermal conduction (Tarnawski et al., 2000, 2011; Tien et al., 2010). Values ii and iii are responsible for increasing the contact between grains and in this way enhancing the number of available heat transfer paths.

Among all the parameters influencing the thermal conductivity of unconsolidated sediments, soil water content and grain size are considered as the most influencing factors on the performance of collectors and ground heat pumps. Therefore, a better knowledge of the relationship between thermal conductivity and water content is required, given the heterogeneity of sedimentary deposits in alluvial plains, and since measured soil thermal property data are currently not always readily available (Bristow et al., 1998; Luo et al., 2016).

In general, in the same saturation condition, granular material shows better thermal performance than fine-grained or cohesive soils (i.e. clay, silty clay and silty loam), due to the high thermal behaviour of its main mineral component, quartz (Moya et al., 1999; Salomone et al., 1984; Saxton et al., 2006). However, in situ, the water content, and, consequently, the heat transfer properties of soil are subjected to natural climate variations on both seasonal and daily basis. The change of values is more pronounced in coarse-grained than in clay and silty dominated sediments. This indicates that well-graded soils can retain a greater amount of water, a very important condition if improved thermal conductivities are desired over time (Di Sipio et al., 2016; Naylor et al., 2015; Usowicz et al., 1996; Smits et al., 2010).

Understanding how (i) drought-saturation variation over time and (ii) vertical and lateral spatial variability of material affect a sediment will contribute to a better design of horizontal ground heat exchangers (HGHE), taking into consideration that heat and mass transfer in soil is a coupled process (Balghouti et al., 2005; Drefke et al., 2017).

As shown by the recently ended ThermoMap EU Project (http://geoweb2.sbg.ac.at/thermomap/), grain size distribution identification is a very significant factor for the calculation of heat conductivity. This allows an assessment of the very shallow geothermal potential (vSGP) of different geological materials. In coarse soil (i.e. sand, fine sand, etc.) characterised by high air capacity, in anhydrous condition, the thermal conductivity is reduced due to the presence of air (a good heat isolator) in the voids. In saturated conditions, when in the pore system the air is replaced by water, the thermal conductivity values are expected to increase, hence, inducing better condition for the transfer of heat in the same sediments. Therefore, the optimal distribution of air capacity and available field capacity that is typical of loamy soils seems to provide the highest thermal conductivity performance over time (Bertermann et al., 2014, 2015). A small addition of a natural additive ( $8 \%$ clay) to a coarse soil (sand), also improves the field capacity of the soil and leads to an increase in the thermal conductivity. This is due to both the pronounced binding effect noticed in nearly anhydrous conditions and to the increase of the sediment water content (Farouki, 1981; Nikolaev et al., 2013; Smits et al., 2010; Tien et al., 2010).

Several thermal conductivity models (mixing, empirical and mathematical) for unsaturated and saturated soils have been proposed so as to identify the controlling physical mechanisms for the thermal behaviour of different soil materials at various unsaturated conditions. Still, only few measured published data are available (Dong et al., 2015; Lu et al., 2007; Smits et al., 2010). However, an increasing number of soil experimental data is required by the scientific community in order to validate and improve the heat and water transport model at disposal and to properly model performance, reliability and environmental impact in the short and long term of shallow geothermal engineering applications (Zhang et al., 2016). Therefore, it is worthy of interest to derive a better comprehension of how the different soil typologies (i.e. sand, loamy sand, etc.) affect and are affected by the heat transfer exchange with VSG installations.

A key challenge is to understand how the thermal properties of different soil typologies change in the same environmental condition. A further challenge is to how to improve heat transfer efficiency of soils through applying thermally-enhanced backfilling material (TEBM) using natural materials and acting on their ability to preserve a constant thermal behaviour in the long term.

Taking into consideration these premises, the ITER Project funded by the European Union, is here presented.

In this paper, we provide an overview of physical-thermal property variations under different moisture and load conditions for different mixtures of natural materials - as based on laboratory data. Of particular emphasis is the analysis of the physical-thermal properties of two natural sediments (fine sand and sand, normally used in building constructions), both as pure and mixed material. Herein, two commercial products readily available on the market (bentonite and clay powder) have been mixed separately with sand in different percentages. In this way, more than 100 samples have been prepared, gradually varying the reference material (pure or with additive), the kind of additive (bentonite or clay), the water content (fresh water gradually added to the dry unconsolidated sediment in incremental steps) and the pressure applied.

\section{MATERIALS AND METHODS}

The laboratory activity involves the analysis of the physical-thermal properties of two coarse sediments (fine sand, sand), both as pure and mixed material, as dependent upon the water content and the bulk density. In addition, a natural sediment (loamy sand), representative of the ITER test site, located in Eltersdorf (Bavaria, Germany), 
is assessed. Two additives are used to create the mixtures, respectively, bentonite and clay powder. Both of these are commercial products readily available on the market. In our work, they have been mixed separately to the coarse sediments in different weight percentages $(8,15$, and $30 \%)$.

The sand bodies used in this research belong to the Burgsandstein Formation (Trias) and have a dominant quartz composition. The material is sieved by the producer up to 1 and $4 \mathrm{~mm}$, respectively. Thus, we can differentiate a fine sand $0-1 \mathrm{~mm}\left(f_{s}\right)$ and a sand $0-4 \mathrm{~mm}(s)$. The loamy sand $(S C)$ is a quaternary sediment belonging to the Hauptterrasse formation (Bayerischen Geologischen Landesamt, 1971).

Regarding the bentonite $(B)$ and clay powder $(C)$, the former is a very fine non-calcareous marine clay, belonging to the Holmehus Formation; the latter is a grey marl-calcareous clay (Lias) collected near the city of Buttenheim (Bavaria, Germany). Each mixture is analyzed under different water content (from dry, up to complete saturation) and under different incremental load steps $(+0,+1,+3,+5 \mathrm{t})$.

From all the mixtures tested, five have been selected as backfilling material for the ITER test site, wherein 5 helixes have been installed horizontally ( $3 \mathrm{~m}$ length), instead of the traditional vertical, and are located at a depth of 0.6-1.1 m below the ground level.

The physical-thermal properties of the selected sediments were first tested in the laboratory in order to identify their behaviour in a controlled environment. The main parameters determined are:

- grain size by sieving the sand fraction $(<63 \mu \mathrm{m})$ of each mixture according to DIN 18123, and then using for the remaining fine particle, the Sedigraph III Plus 5125 (Syvitski, 2007). The Sedigraph measures the grain size distribution of the sample by means of X-ray radiation based on the sedimentation theory (Stokes's law) and the adsorption of X-rays (Beer-Lambert law) (Webb, 2004);

- mineralogical content via the X-Ray Diffraction (XRD) technique, using reference intensity ratio (RIR) methodology on powder samples (PanAnalytical X'Pert Pro instrument). Due to the presence of clay minerals, a semiquantitative data processing is preferred in order to obtain information regarding the relative concentrations of elements in each sample. This is done by comparing the spectral data registered by the instrument (Rietveld, 1969; Hillier, 2000);

- thermal conductivity by thermal properties analyser (KD2Pro apparatus, Decagon Devices, Inc.). The device consists of a handheld controller and a single needle sensor probe (TR-1, $2.4 \mathrm{~mm}$ diameter, $10 \mathrm{~cm}$ long needle) operating according to the transient line source method (ASTM D5334-08, Naylor et al., 2015);

- moisture content by time-domain reflectometry (TDR) device (TRIME IMKO GmBH). The device allows the determination of the soil moisture content (probe range
$0-100 \%$ ), empirically related to the apparent dielectric constant (ka) of the soil (IMKO Micromodultechnik GmbH; Susha Lekshmi et al., 2014);

- bulk density as determined on a duly collected sample (for every moisture content step and load) according to the DIN 52102-2;

- water content as determined on a duly collected sample (for every moisture content step and load) according to the DIN 18121-1.

Starting from the pure dried material $\left(f_{S,}, B, C\right), 16$ mixtures were tested according to the methodological approach hereafter described, excluding the two additives formed by pure cohesive materials (Table 1). From the bulk density and water content analysis, other physical parameters were calculated (i.e. porosity, volumetric water content etc.).

In line with the laboratory approach already described in the GeoSurf Project (Bertemann and Schwarz, 2017), the lab operating phases of ITER Project are summarised as follows (Fig. 1):

1. each pure material is air dried in a ventilated room at a temperature between $18-22^{\circ} \mathrm{C}$; then, once dried, the cohesive additive is added gradually to the pure material so as to constitute 8,15 , and $30 \%$ of the total weight available (about $60 \mathrm{~kg}$ ) as foreseen in Table 1; a standardised concrete mixer (140 1, $26.6 \mathrm{RPM}, 650 \mathrm{~W})$ is used, allowing a homogeneous distribution of the components;

2. once ready, each mixture is collected in a plastic box with internal dimension $56 \times 36 \times 28 \mathrm{~cm}$ and a volume of about $56 \mathrm{dm}^{3}$. This large volume is conceived to minimise the boundary effect of the box on the probes and to simulate reliable field test condition (Fig. 1a-c);

3 . each cycle of measurement consists of 2 thermal conductivity, 4 moisture content and bulk electrical resistivity and 1 electrical resistivity acquisition as shown in Fig. 1a. In addition, a sample of material is collected to determine the bulk density, the volumetric water content and the grain size distribution (Fig. 1d);

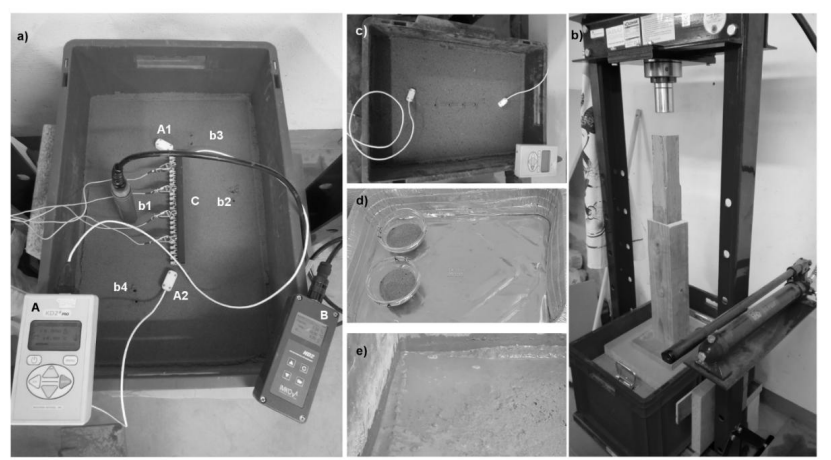

Fig. 1. Laboratory operating phases: a - a cycle of measurement consisting of two thermal conductivity (A1-2), four moisture content and bulk electrical resistivity (b1-4) acquisitions on a soil body $(C) ; b$ - the workshop press to apply the incremental pressure steps; $\mathrm{c}-\mathrm{a}$ detail of the thermal measurement; $\mathrm{d}$ - samples collected to determine bulk density and volumetric water content of the mixture; e - example of water content exciting the field capacity of the material. 
Table 1. The complete set of mixtures analyzed in the ITER laboratory testing

\begin{tabular}{|c|c|c|}
\hline Pure material & ITER mixtures & Sample code* \\
\hline \multirow{9}{*}{ fine sand $0-1 \mathrm{~mm}$} & pure & $f_{s}$ \\
\hline & \multicolumn{2}{|c|}{ with Bentonite (\%) } \\
\hline & 8 & $f_{s} 8 B$ \\
\hline & 15 & $f_{s} 15 B$ \\
\hline & 30 & $f s 30 B$ \\
\hline & \multicolumn{2}{|c|}{ with Clay (\%) } \\
\hline & 8 & $F_{s} 8 C$ \\
\hline & 15 & $f_{s} 15 C$ \\
\hline & 30 & $f_{s} 30 C$ \\
\hline \multirow{9}{*}{ sand $0-4 \mathrm{~mm}$} & pure & $s$ \\
\hline & \multicolumn{2}{|c|}{ with Bentonite (\%) } \\
\hline & 8 & $s 8 B$ \\
\hline & 15 & $s 15 B$ \\
\hline & 30 & $s 30 B$ \\
\hline & \multicolumn{2}{|c|}{ with Clay (\%) } \\
\hline & 8 & $s 8 C$ \\
\hline & 15 & $s 15 C$ \\
\hline & 30 & $s 30 C$ \\
\hline $\begin{array}{l}\text { loamy sand } \\
\text { Eltersdorf }\end{array}$ & pure & $S C$ \\
\hline $\begin{array}{l}\text { sand } 0-5 \mathrm{~mm} \\
\text { Eltersdorf* }\end{array}$ & pure & $s-E L T^{* *}$ \\
\hline
\end{tabular}

${ }^{*} B$ - bentonite and $C$ - clay powder; the two additives are tested also for grain size and mineralogical composition; **s-ELT is the sand used in the test field in Eltersdorf, available at the time of case study set-up. It belongs to the Burgsandstein Formation, but the grain size range stated by the producer is between $0-5 \mathrm{~mm}$. Tested only for grain size distribution.

4. the entire cycle is repeated four times (1 series of measurements) for each dry mixture, varying the pressure exerted on the material with a workshop press (max load $20000 \mathrm{~kg}$, Fig. 1b), according to four incremental pressure loads of $+75,+1000,+3000,+5000 \mathrm{~kg}$ (corresponding to $+3.6,+48.6,+145.9$, and $+243.2 \mathrm{kPa})$;

5. fresh water is added gradually to the anhydrous unconsolidated sediment under testing, in incremental steps equal to $2.5 \%$ by weight of the dry mixture, until the field capacity is overcome. In this final step, consolidation is no more possible and a displacement of soft soil is registered - as disaggregation comes about due to the elimi- nation of the friction force between sand grains because of the high water content (Fig. 1e). To obtain a homogeneous distribution of the water content, the water is added using a small cement mixer and a commercially available spray flask. Once a new saturation degree is obtained, the measurements described at point 3-4 are repeated for every saturation step;

6. the mineralogical content is determined only for the pure material $(f s, s, B, C, S C)$.

In accordance with the laboratory working plan, more than 100 samples were prepared, gradually varying the reference material (pure or with additive), the kind of additive (bentonite or clay), the water content (fresh water added gradually to the dry unconsolidated sediment in incremental steps) and the pressure applied.

We chose to perform measurements on large volumes of materials (about $56 \mathrm{dm}^{3}$ ) rather than the usual laboratory scale in order to make the results comparable with the results given at local scale (i.e. field test), and to minimise the scale effect (Bertermann and Schwarz, 2017; Kömle et al., 2007; Moya et al., 1999).

\section{RESULTS}

The grain size classification of ITER mixtures is based on the USDA (United States Department of Agriculture) textural soil classification system, where three main classes of soil are identified according to the size of their particles:

- sand ranging from 2 to $0.05 \mathrm{~mm}$,

- silt from 0.05 to $0.002 \mathrm{~mm}$,

- and clay for particles with a diameter less than $0.002 \mathrm{~mm}$ (USDA, 1987).

In addition, the sand fraction is subdivided into another five subcategories (very coarse: 2.0 to $1.0 \mathrm{~mm}$, coarse: 1.0 to $0.5 \mathrm{~mm}$, medium: 0.5 to $0.25 \mathrm{~mm}$, fine: 0.25 to $0.10 \mathrm{~mm}$, and very fine: 0.10 to $0.05 \mathrm{~mm}$ ).

According to this classification, the selected ITER mixtures are defined as sand $(f s, s, s-E L T, s 8 B, s 8 C, s 15 C)$, loamy sand $\left(S C, f_{s} 8 B, f_{s} 8 C\right)$, sandy loam $\left(f_{s} 15 B, f_{s} 15 C\right.$, $\left.s 15 B, f_{s} 30 C, s 30 C\right)$ and sandy clay loam $\left(f_{s} 30 B, s 30 B\right)$ as the clay content increases. The two additives belong to the clay $(B)$ and silt loam $(C)$ groups, respectively (Fig. 2).

All the soil samples, except the pure bentonite and clay powder used as additives, have a high sand content, ranging between 60 and $100 \%$. The particle-size distribution curves revealed these to be either poorly graded soils differentiating into uniform soils in which most particles have the same size $(f s, s, s 8 B, s-E L T, C)$ that are constituted mainly of pure or natural materials, or as gap-graded soils, where intermediate sizes (usually in the silt fraction) are missing (the last are typical of the mixtures) (Fig. 3). Only the clay powder is defined as a well-graded soil, and is characterised by values of $\mathrm{Cu} \geq 6$ and $\mathrm{Cc}$ within the range $1 \div 3$, where $\mathrm{Cu}$ is the coefficient of uniformity and $\mathrm{Cc}$ the coefficient of the curvature of the grain-size curve (USDA, 2012). 


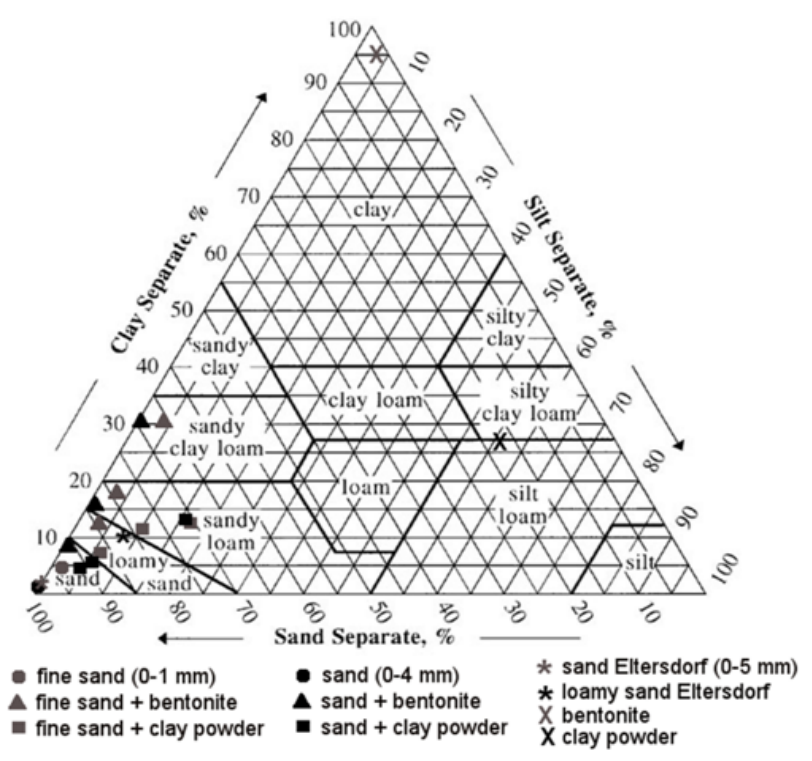

Fig. 2. Grain size classification of ITER mixtures based on the USDA textural soil classification.
In each domain ( $f s$ or $s$ ), the trend of the granulometric curves obtained by adding 8,15 and $30 \%$ by weight of $\mathrm{C}$ or $\mathrm{B}$ is easily identifiable. In fact, an increment in $\mathrm{C}$ content provides a convex shape to each particle-size curve, the convexity of which decreases as the additive percentage increases. Of note, the increase in B results in an inversion of the concavity of the curve at about $0.2 \mu \mathrm{m}$ (typical of pure bentonite). In both trends, the smoothening effect seems greater in $f_{s}$ than in $s$ compounds.

In this framework, the natural material typical of the ITER test site (SC), a loamy sand, covers an intermediate position between sand and fine sand mixtures, and its trend seems delimited by those of $f_{s} 8 B, f_{s} 8 C$ and $s 15 B$ materials. Moreover, no substantial textural differences are observed between the sand 0-4 $(s) \mathrm{mm}$ used in laboratory and the sand $0-5 \mathrm{~mm}(s-E L T)$ adopted in situ, so these materials are assumed to be comparable for ITER research purposes.

Compositional analysis by X-ray diffraction method was performed on five soil samples that either are of the original material used to create the thermally enhanced

a

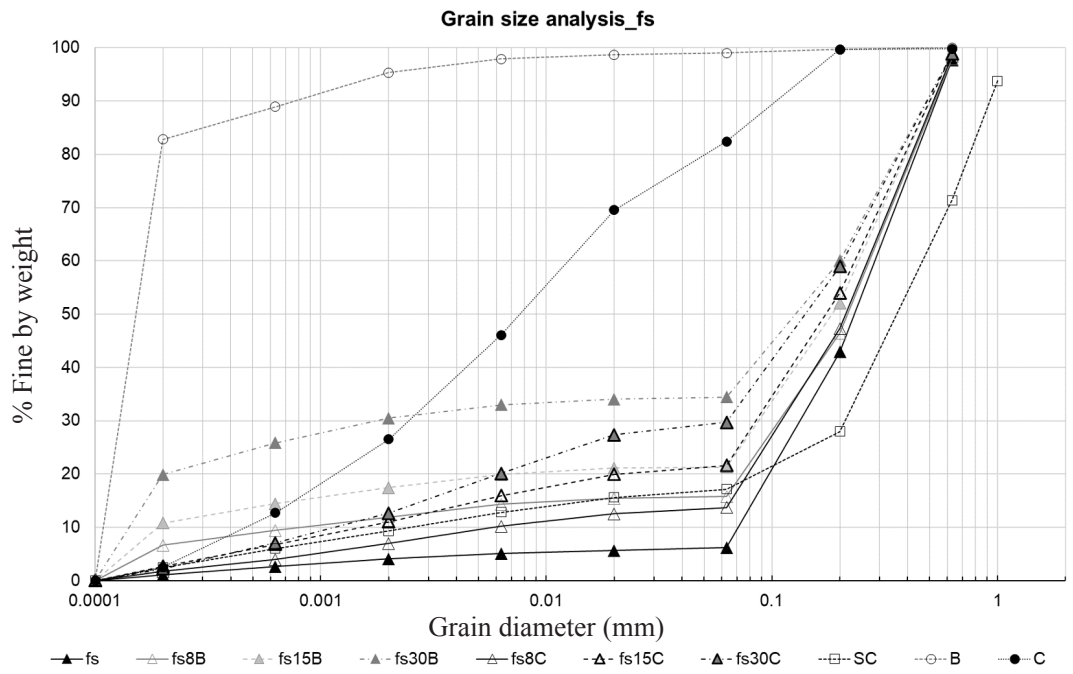

b

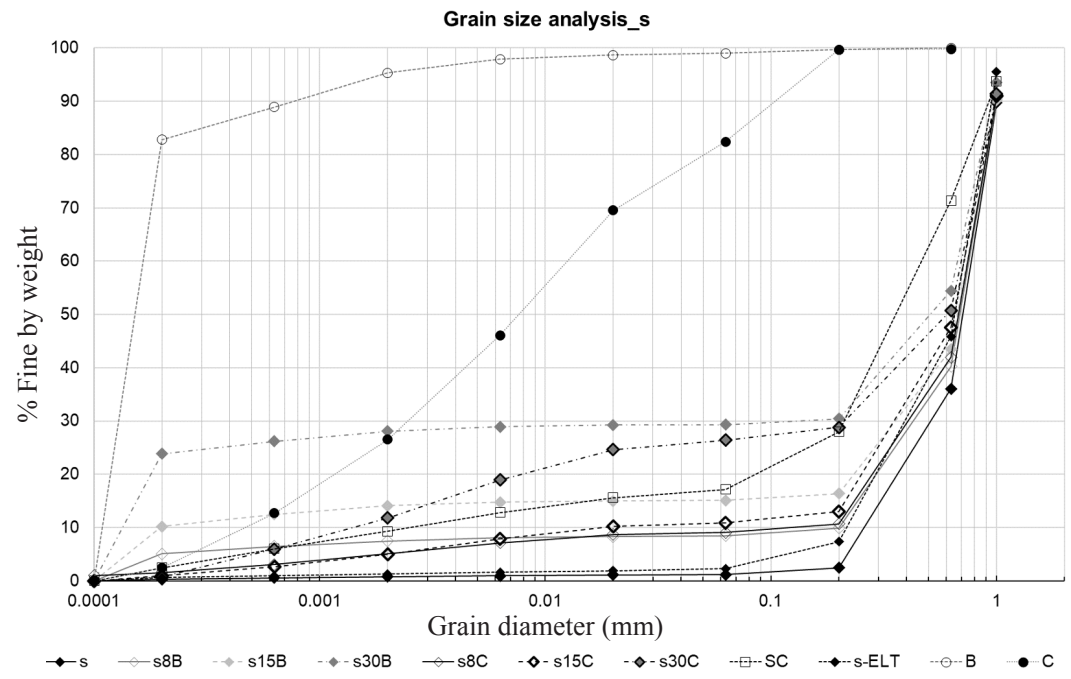

Fig. 3. Grain size curves for the mixtures with prevalent fine sand (a) and sand (b) composition. 
backfilling material (TEBM) mixtures tested in laboratory, or the natural soil available at the test site location. Moreover, fine $(f s)$ and coarse $(s)$ sands, loamy sand $(S C)$, bentonite $(B)$ and clay powder $(C)$ were tested so as to identify the main mineralogical phases and their amounts.

As shown by the results (Table 2), the soil mineralogy is dominated by quartz, the main component of $f s, s, S C$ and $C$, while montmorillonite is the dominant phase for $B$.

Once the soils were air-dried, sieved, and moistened, direct measurements of thermal conductivity, bulk density and water content were performed on more than 400 samples. Based on these results, information about volumetric water content $(\theta)$, porosity $(\varphi)$ and saturation (S) were calculated as described in the 'Material and methods' section.

The thermal conductivity $(\lambda)$ values of TEBM tested at all pressure load and moisture content steps ranged between 0.199 and $2.909 \mathrm{~W} \mathrm{~m}^{-1} \mathrm{~K}^{-1}$. The sand mixtures reached higher values than did fine sand compounds: the

Table 2. Relative concentrations of mineralogical phases by XRF measurement for a selection of ITER soil samples, constituted by the pure material used to create the different mixtures tested in the laboratory

\begin{tabular}{|c|c|c|c|}
\hline Pure material & $\begin{array}{l}\text { Mineralogical } \\
\text { phase }\end{array}$ & $\begin{array}{l}\text { Weight } \\
\text { fraction } \\
(\%)\end{array}$ & Note \\
\hline $\begin{array}{l}f_{S} \\
\text { (fine sand } 0-1 \mathrm{~mm} \text { ) }\end{array}$ & $\begin{array}{l}\text { quartz } \\
\text { orthoclase } \\
\text { albite } \\
\text { muscovite/illite }\end{array}$ & $\begin{array}{r}85 \\
6 \\
4 \\
5\end{array}$ & $\begin{array}{l}\text { presence } \\
\text { of } \\
\text { smectite* }\end{array}$ \\
\hline $\begin{array}{l}s \\
\text { (sand 0-4 mm) }\end{array}$ & $\begin{array}{l}\text { quartz } \\
\text { orthoclase } \\
\text { microcline }\end{array}$ & $\begin{array}{r}92 \\
6 \\
2\end{array}$ & \\
\hline $\begin{array}{l}S C \\
\text { (loamy sand } \\
\text { Eltersdorf) }\end{array}$ & $\begin{array}{l}\text { silicon oxide } \\
\text { microcline } \\
\text { calcium carbonate } \\
\text { muscovite/illite } \\
\text { kaolinite }\end{array}$ & $\begin{array}{r}80 \\
14 \\
1 \\
4 \\
1\end{array}$ & \\
\hline $\begin{array}{l}B \\
\text { (bentonite) }\end{array}$ & $\begin{array}{l}\text { quartz } \\
\text { anatase } \\
\text { orthoclase } \\
\text { clinoptilolite } \\
\text { clinochlore } \\
\text { montmorillonite } \\
\text { muscovite/illite }\end{array}$ & $\begin{array}{r}16 \\
1 \\
3 \\
1 \\
2 \\
61 \\
16\end{array}$ & $\begin{array}{l}\text { presence } \\
\text { of } \\
\text { smectite/ } \\
\text { illite* }\end{array}$ \\
\hline $\begin{array}{l}C \\
\text { (clay powder) }\end{array}$ & $\begin{array}{l}\text { quartz } \\
\text { pyrite } \\
\text { kaolinite } \\
\text { calcite } \\
\text { clinochlore } \\
\text { muscovite }\end{array}$ & $\begin{array}{r}45 \\
1 \\
19 \\
3 \\
7 \\
25\end{array}$ & $\begin{array}{l}\text { presence } \\
\text { of } \\
\text { smectite/ } \\
\text { illite* }\end{array}$ \\
\hline
\end{tabular}

*The presence of a small amount of smectite or interbedded smectite/illite phase is possible. However, the relative amount is not quantifiable because superimposed to the muscovite/illite peak. former had an average and a maximum value of 1.421 and $2.909 \mathrm{~W} \mathrm{~m}^{-1} \mathrm{~K}^{-1}$, the latter, of 1.187 and $2.179 \mathrm{~W} \mathrm{~m}^{-1} \mathrm{~K}^{-1}$, while the minimum values in dry condition were similar $\left(\approx 0.200 \mathrm{~W} \mathrm{~m}^{-1} \mathrm{~K}^{-1}\right)$.

The volumetric water content ranged between 0 and $49.07 \%, \mathrm{~m}^{3} \mathrm{~m}^{-3}$, wherein the lowest values belong to the coarse sand and the highest to the $f_{s} 30 B$ mixture. For equal amounts of additive inserted in the same basic material ( $f s$ or $s$ ), the contribution of bentonite exceeded that of the clay powder in the ability to retain water: $\theta$, on average, was about 23.84 and $15.31 \%, \mathrm{~m}^{3} \mathrm{~m}^{-3}$ for $f_{S} B$ and $f_{S} C$ mixtures, 19.78 and $13.10 \%, \mathrm{~m}^{3} \mathrm{~m}^{-3}$ for $s B$ and $s C$ mixtures, $16.13 \%, \mathrm{~m}^{3} \mathrm{~m}^{-3}$ for the loamy sand.

The variation of the saturation levels in each TEBM demonstrated the achievement of partially - and oversaturated conditions $\left(70 \%<\mathrm{S}_{\max }<127 \%\right)$ as evolved from unsaturated soil conditions $\left(0<\mathrm{S}_{\min }<7 \%\right)$.

The porosity ranged between 20.91 and $63.47 \%$. Herein, as expected by grain size analysis, $f_{s}$ compounds had higher mean value than $s$ compounds (47.36 vs $36.87 \%$ ). In addition, on average, according to the classification for bulk density of the German soil mapping instructions (Ad-hocAG-Boden, 2005), the former group presented - 'low' $\left(\approx 1.39 \mathrm{~g} \mathrm{~cm}^{-3}\right)$, the latter - 'medium' bulk density levels $\left(\approx 1.67 \mathrm{~g} \mathrm{~cm}^{-3}\right)$.

The relationship between thermal conductivity and volumetric water content of soils, as well known by literature, showed an increment in $\lambda$ as $\theta$ increased (Fig. 4). Plotting all the results together, it is possible to recognise four different domains which describe the general behaviour of the mixtures, the range and boundaries of which depends on the physical properties of the soil (Alritmi et al., 2016; Bristow, 1998; De Vries, 1963; Dong et al., 2015; Lu et al., 2007; Tarnawsky and Gori, 2002; Smits et al., 2010). According to Tarnawsky and Gori (2002), the boundaries between the four regions (residual, transitory meniscus, micro/macro-porous capillary and superfluous) are: the critical value of volumetric moisture content $\left(\theta_{c r}\right)$; the permanent wilting point $\left(\theta_{P W P}\right)$; and the field capacity $\left(\theta_{F C}\right)$, wherein $P W P$ and $F C$ are defined, respectively, as the minimal point of soil moisture the plant requires not to wilt, and the value of water content remaining in a unit volume of soil after downward gravity drainage has materially ceased (Bertermann et al., 2013; Farouki, 1981; Nikolaev et al., 2013). Once the clay content of a soil is known, $\theta_{c r}$ and $\theta_{P W P}$ can be defined as follows:

$$
\theta_{c r}=\mathrm{c} \theta_{P W P},
$$

and

$$
\theta_{P W P}=0.026+0.5 m_{\text {clay }}
$$

where: $\mathrm{c} \approx 0.375$ and $m_{\text {clay }}$ is the soil clay content (Tarnawsky and Gori, 2002). 


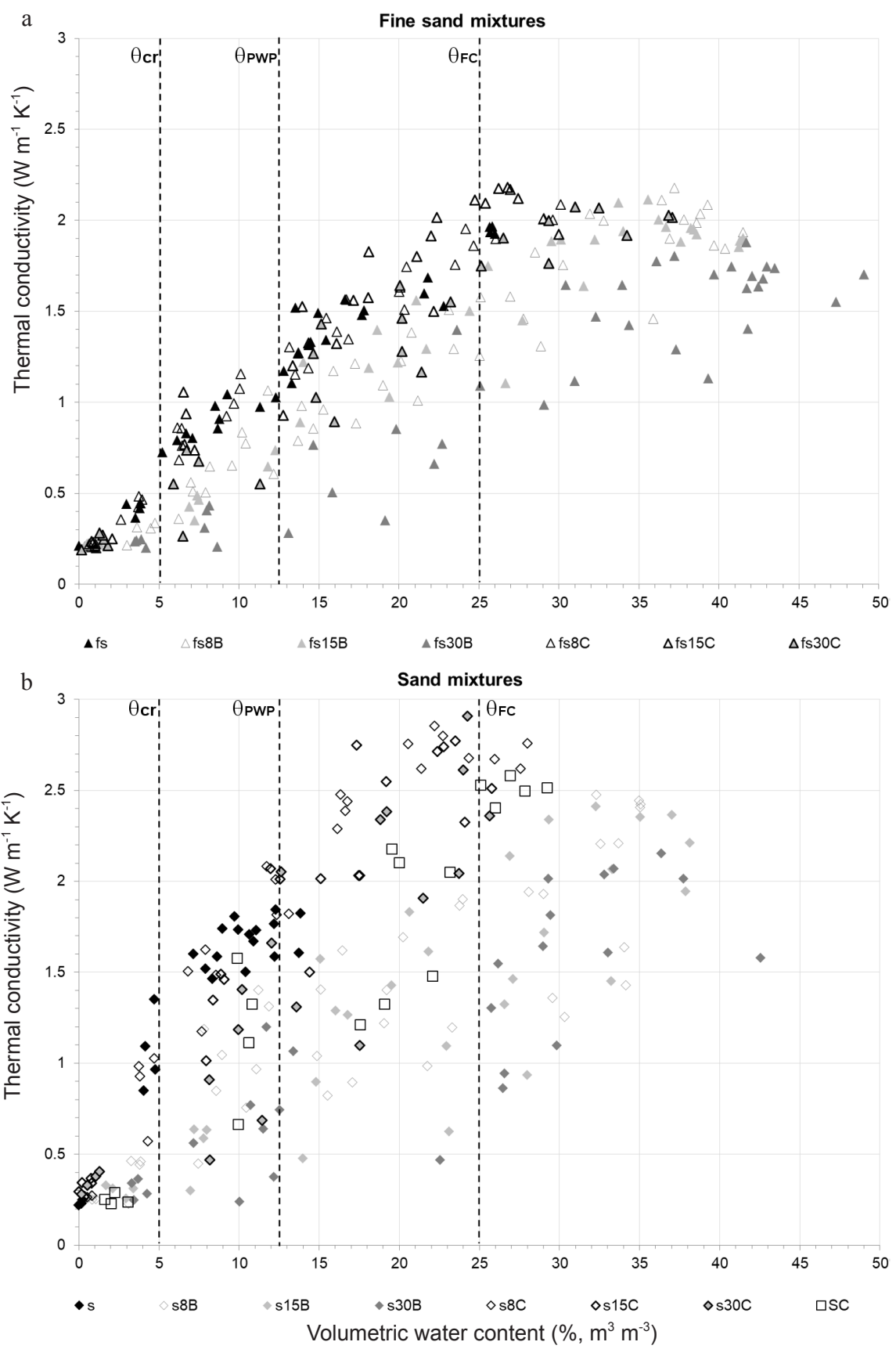

Fig. 4. Relationship between thermal conductivity and volumetric water content for ITER mixtures: graphical representation of the measurement performed on the fine (a) and coarse (b) textured material comprehensive of all the different pressure conditions and moisture content levels created within the laboratory.

However, when sediments characterised by different grain sizes are compared, it is difficult to define a unique boundary. In this study, where most of the material falls within the sandy loam region, the $\theta_{c r}$ and $\theta_{P W P}$ values of loam, equaled 5 and $12.5 \%, \mathrm{~m}^{3} \mathrm{~m}^{-3}$, respectively, and are considered as the top reference limits for the residual and transitory domains.

For ITER samples, in the residual domain $\left(0<\theta<\theta_{c r}\right)$ at low degree of volumetric water content $\left(<5 \%, \mathrm{~m}^{3} \mathrm{~m}^{-3}\right)$, the $\lambda$ barely changed $\left(0.180<\lambda<0.500 \mathrm{~W} \mathrm{~m}^{-1} \mathrm{~K}^{-1}\right)$, both for fine and coarse sand mixtures for any pressure stage
(Fig. 3). The heat transfer here occurred mainly through contact points between soil particles and was hampered by the presence of air in the voids, while the water adhered to particle surfaces.

Then, a further increase of moisture in the transitory domain $\left(\theta_{c r}<\theta<\theta_{P W P}\right)$ showed a rapid rise of thermal conductivity in all the mixtures. This came about due to the creation of water bridges between soil grains, able to greatly enhance $\lambda$ at low water content $\left(<12.5 \%, \mathrm{~m}^{3}\right.$ $\mathrm{m}^{-3}$ ). In addition, the $\lambda$ evolution with changing degree of moisture content was steeper for the pure sand sediments 

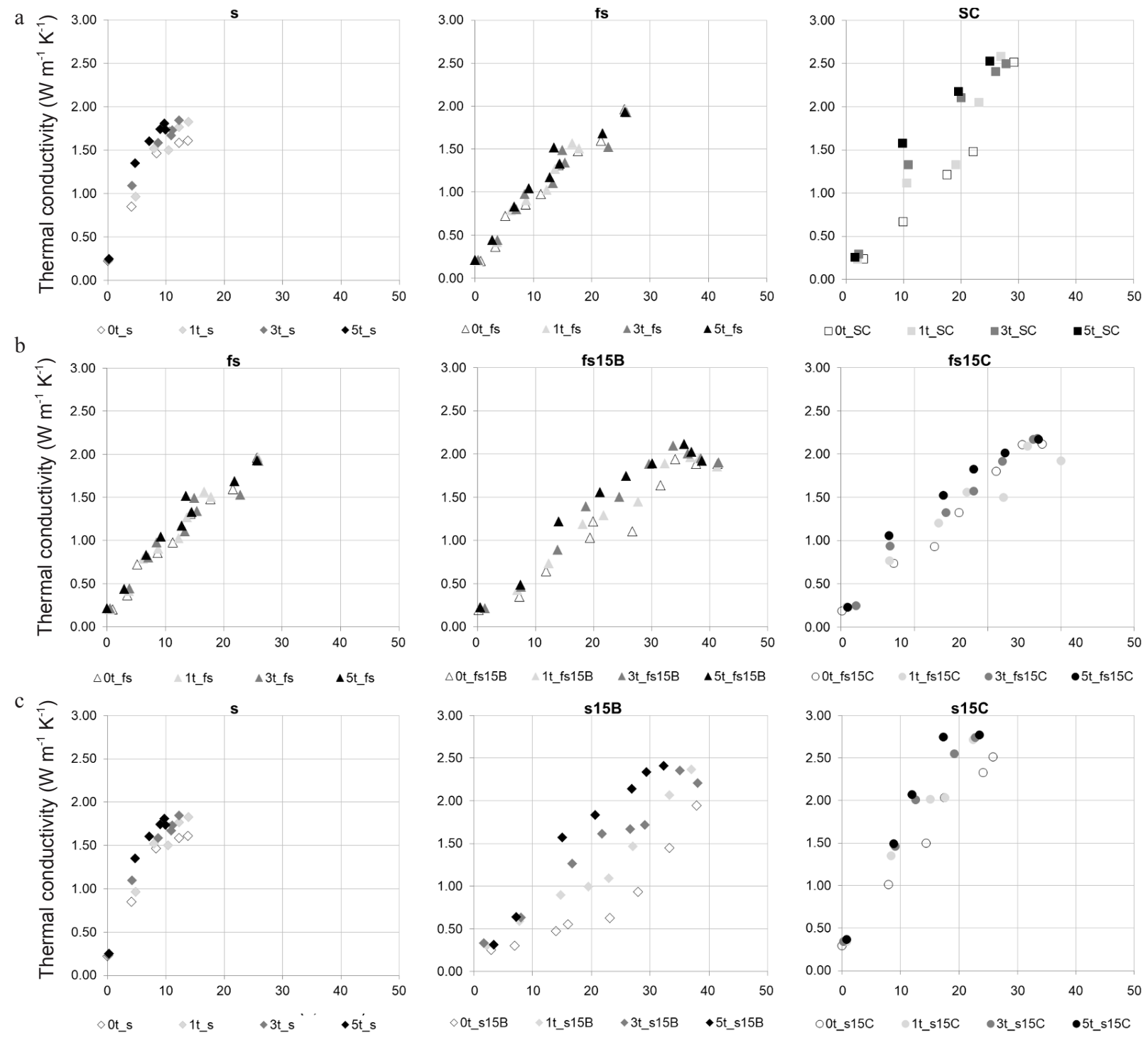

Volumetric water content $\left(\%, \mathrm{~m}^{3} \mathrm{~m}^{-3}\right)$

Fig. 5. Example of $\lambda$ vs $\theta$ relationship for specific ITER mixtures: trends for fine sand, sand and loamy sand sediments differentiated according to the pressure load exerted (a); trends of mixtures with prevalent fine sand (b) and sand (c) composition differentiated according to the pressure load exerted and the percentage of clay or bentonite additive used. In the caption, the pressure load steps are shown in tonnes and the first step $(75 \mathrm{~kg})$ is cited as $0 \mathrm{t}$.

( $f s$ and $s$ ) as compared to the mixed materials, and was smoother in fine than in coarse sand compounds (Fig. 4). What is more, the trend was even more dampened in soil characterised by a greater porosity, that is when bentonite instead of clay powder was added (Figs 4-5). For example, in the $\theta$ range $5-12.5 \%, \mathrm{~m}^{3} \mathrm{~m}^{-3}, \lambda$ reached maximum values of about $1.8,1.5$ and $1.2 \mathrm{~W} \mathrm{~m}^{-1} \mathrm{~K}^{-1}$ for $s, S C$, $f_{S}$ and 2.0, 1.0, $1.3,1.1 \mathrm{~W} \mathrm{~m}^{-1} \mathrm{~K}^{-1}$ for $s C, s B, f_{s} C, f_{s} B$ mixtures. A possible explanation for this phenomena is that in fine textured soils, characterised by particles with larger surface areas, more water is required to create the water bridges, so, on one hand, the $\lambda$ increase with $\theta$ is faster in coarse textured soils, and, on the other, greater $\theta$ values are obtained in the fine textured soils.
Beyond the $\theta_{P W P}$ limit, the third domain began. This is the micro/macro-porous capillary region $\left(\theta_{P W P}<\theta<\right.$ $\theta_{F C}$ ), wherein a gradual and slower growth of $\lambda$ with $\theta$ was observed, due to the progressive replacement of air with water in the pore voids. In this case, the upper limit $\left(\theta_{F C}=25 \%, \mathrm{~m}^{3} \mathrm{~m}^{-3}\right)$ for the TEBM was derived by graphical observation, because after this threshold, a further increase of water content did not affect the heat flow growth. However, in TEBM with a higher percentage of clay material or bentonite, the $\theta_{\mathrm{FC}}$ limit could be shifted towards a greater moisture content value (i.e. $\theta_{F C}>35 \%, \mathrm{~m}^{3} \mathrm{~m}^{-3}$ for $f_{S} 30 B$ or $30 \%, \mathrm{~m}^{3} \mathrm{~m}^{-3}$ for $\left.s 30 B\right)$, because the finer grain size requires more water content to reach saturated condition. 
The maximum values of thermal conductivity measured in the laboratory belong to this domain and were equal to $2.909,2.582$ and $2.179 \mathrm{~W} \mathrm{~m}^{-1} \mathrm{~K}^{-1}$ for the coarse sand mixtures, the natural material (loamy sand) and the fine sand mixtures (Fig. 4).

Finally, in the superfluous water domain $\left(\theta>\theta_{F C}\right)$, the thermal conductivity is not more influenced by the increase of pore water in the voids. Given that the air displacement in the voids is not more effective, drainage is possible and near saturation conditions were reached, hence, $\lambda$ values in this regime were constant or could have slowly decreased. For example, $\lambda$ trend for mixtures with $\theta_{F C}>25 \%, \mathrm{~m}^{3} \mathrm{~m}^{-3}$ showed values decreasing slowly between $2.2-1.5$ and 2.9-1.5 $\mathrm{W} \mathrm{m}^{-1} \mathrm{~K}^{-1}$ for fine and coarse sand mixtures, respectively (Fig. 4).

The influence of the grain size on thermal conductivity can be easily observed in Fig. 5. Fine grained materials showed generally lower $\lambda$ values than did the corresponding coarse-grained materials when the volumetric moisture content increased (Figs 4 and 5). Thus, adding an additive to a pure material enriched in quartz (i.e. $f s$ and $s$ ) reduces its capacity to transfer heat: the greater the amount added ( $30 \%$ of additive), the greater the observed reduction compared to the original soil (Figs 4, 5b, c). The increased number of grain contacts due to the presence of finer material, clay powder $(C)$ or bentonite $(B)$ is responsible for an increase of the thermal resistance between grains, and, consequently, slightly diminishes the $\lambda$ values.

However, the mineralogical composition of the additive also plays a role in the $\lambda$ variation. Because of the $45 \%$ quartz mineralogical composition (quartz holds a good performance as heat transfer medium), the addition of clay powder, in any percentages, to $f s$ and $s$, did not result in a sharp decrease in values for any pressure steps considered. Instead, an increased amount of bentonite, characterised mainly by clay minerals, was responsible, on one hand, for a lowering of the heat transfer values, and, on the other, for a gain in the capacity for retaining moisture, when compared both to pure material and to the clay compounds (Fig. 5b, c). The ability to retain water is really important if high and constant thermal conductivities are desired for a VSG system. Given the very shallow installation depth required by horizontal heat exchangers, if a soil, as $f s$ and $s$, shows a large change in $\lambda$ for a small water content variation, induced, for example, by atmospheric and/or environmental condition, the efficiency of the system can be compromised. Therefore, a soil able to vary gradually its $\lambda$ content with a reduction of $\theta$ is preferable to ensure over time a constant performance of the VSG system.

Variation in bulk density $(\rho)$ affected all the tested soils. A rise in $\rho$ values was also related to a parallel decrease in porosity, because the number of contact points between solid particles increased.
As shown in Fig. 5, in the same moisture condition, an increase of the pressure load from +75 to $+5000 \mathrm{~kg}$ determined an improvement of the heat transfer ability in all the mixtures tested. In addition, the gap between the measurements performed at the lowest $(+75 \mathrm{~kg})$ and greatest pressure step $(+5000 \mathrm{~kg})$ increased as the percentage of clay powder or bentonite in the compounds increased. A wider distribution of the results was observed when a $30 \%$ enhancement of additive was added to the pure material.

For example, taking into consideration the $\lambda$ value recorded in seven mixtures selected as representative of pure materials $\left(f_{s}, s\right)$, natural soil $(S C)$ and TEBM $\left(f_{s} 30 B\right.$, $s 30 B, f s 30 C, s 30 C$ ), for the same volumetric water content (about $10 \%, \mathrm{~m}^{3} \mathrm{~m}^{-3}$ ), the relative difference between the first and fourth pressure step was about 14 and $15 \%$ for $f_{S}$ and $s, 137 \%$ for $S C, 110$ and $222 \%$ for $f_{s} 30 B$ and $s 30 B, 158$ and $199 \%$ for $f_{s} 30 C$ and $s 30 C$.

The relationship between thermal conductivity and bulk density for the whole set of ITER measurements, performed in different consolidation and moisture steps, highlighted the direct correlation between this two properties (Fig. 6). According to literature, a rise in $\rho$ is related to an increase of $\lambda$ (Abu-Hamdeh and Reeder, 2000; Abu-Hamdeh et al., 2001). Thus, with regard to the classification proposed by the German soil mapping authority (Ad-hoc-AG-Boden, 2005), five bulk density classes could be identified:

- 'very low' $\left(\rho<1.2 \mathrm{~g} \mathrm{~cm}^{-3}\right)$,

- 'low' $\left(1.2<\rho<1.4 \mathrm{~g} \mathrm{~cm}^{-3}\right)$,

- 'medium' $\left(1.4<\rho<1.6 \mathrm{~g} \mathrm{~cm}^{-3}\right)$,

- 'high' $\left(1.6<\rho<1.8 \mathrm{~g} \mathrm{~cm}^{-3}\right)$,

- 'very high' $\left(\rho>1.8 \mathrm{~g} \mathrm{~cm}^{-3}\right)$.

Following this system, the ITER fine grained mixtures fell mainly in the 'low' and 'medium' classes (Fig. 6a), while the ITER sand grained compounds belonged to the 'medium' and 'high' ranges (Fig. 6b).

In both groups, the samples characterised by low $\lambda$ levels $\left(<0.500 \mathrm{~W} \mathrm{~m}^{-1} \mathrm{~K}^{-1}\right)$ showed a wide distribution of $\rho$ values, typical of (i) pressure load not representative of natural soil consolidation conditions $(75 \mathrm{~kg}=3.6 \mathrm{kPa})$ and (ii) unsaturated sediments $\left(\theta<5 \%, \mathrm{~m}^{3} \mathrm{~m}^{-3}\right)$. Above this limit, a linear correlation $\left(\mathrm{R}^{2}\right.$ ranging from 0.71 for $f s 30 B$ to 0.95 for $f s 8 C$ ) well-described the behaviour of each fine grained mixture, while the sand grained samples were characterised by a greater dispersion of the values (especially pure sand and bentonite compounds) as the bulk density increased (Fig. 6).

In the first case, both bentonite and clay powder TEBMs presented higher values of $\rho$ than did the pure fine sand. Thus, $f_{s}$ belonged to the 'very low' - 'low' density classes, $f_{s} 8 b-f_{s} 8 C-f_{s} 15 B-f_{s} 15 C$ fell mainly in the 'low' and 'medium' density classes and $f s 30 B-f s 30 C$ varied between the 'medium' and 'very high' range. All tested sediments reached thermal conductivity around $2 \mathrm{~W} \mathrm{~m}^{-1} \mathrm{~K}^{-1}$ and the bentonite compounds showed the highest volumetric water content $\left(>40 \%, \mathrm{~m}^{3} \mathrm{~m}^{-3}\right)$ (Fig. 6c). 

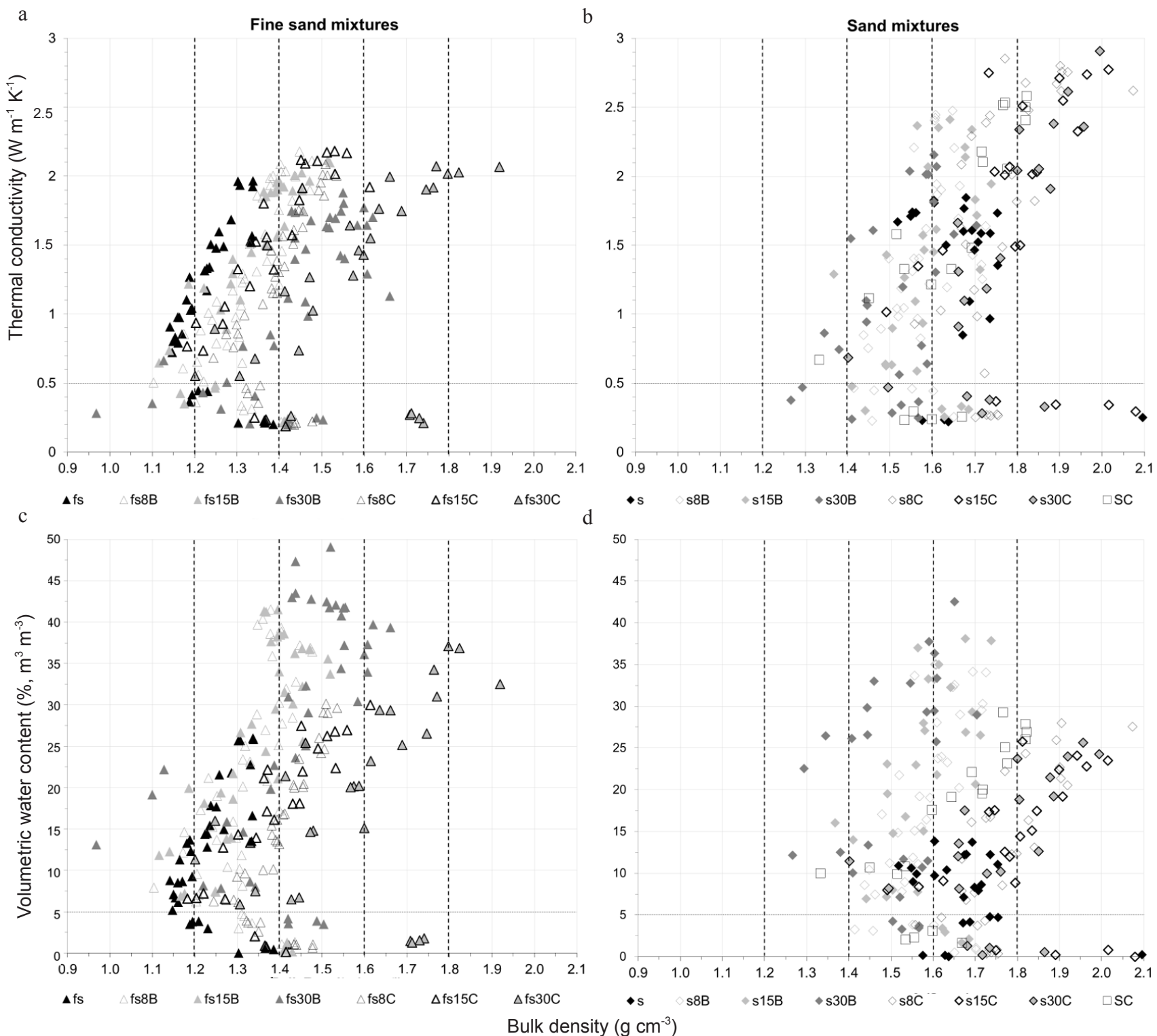

Fig. 6. Relationship between thermal conductivity and bulk density for ITER fine (a) and coarse (b) textured materials; graphical representation of the volumetric water content/bulk density trend for the mixtures with prevalent fine sand (c) and sand (d) composition differentiated according to the additive percentage (clay or bentonite) used.

In the second case, the pure coarse sand belonged to the 'high' bulk density region, the sand-bentonite mixtures $(s 8 B-s 15 B-s 30 B)$ - to the 'low' - 'medium' ranges and the sand-clay mixtures - mainly to the 'high' - 'very high' classes. Moreover, the sand-clay powder mixtures showed the highest values of $\lambda\left(>2.5 \mathrm{~W} \mathrm{~m}^{-1} \mathrm{~K}^{-1}\right)$ with intermediate volumetric water content $\left(\theta<30 \%, \mathrm{~m}^{3} \mathrm{~m}^{-3}\right)$, while the bentonite compounds presented the highest capacity to retain water $\left(\theta>30 \%, \mathrm{~m}^{3} \mathrm{~m}^{-3}\right)$ and lower thermal conductivity $\left(<2.5 \mathrm{~W} \mathrm{~m}^{-1} \mathrm{~K}^{-1}\right)$. Finally, the loamy sand (SC) was characterised by a wide range of bulk density values (from 'low' to 'very high'), maximum $\lambda$ and $\theta$ values of about $2.5 \mathrm{~W} \mathrm{~m}^{-1}$ $\mathrm{K}^{-1}$ and $30 \%, \mathrm{~m}^{3} \mathrm{~m}^{-3}$, respectively (Fig. 6d).
The results discussed until now are representative of tests performed in laboratory, under controlled and reproducible conditions. When dealing with the in-situ test site, meteorological and environmental aspects can impact on the volumetric water content distribution at surface and at depth, affecting in this way, the heat transfer capacity of the soils.

Taking into consideration a pressure step equal to $1000 \mathrm{~kg}$, where $1000 \mathrm{~kg}$ stands for soil consolidation at approximately 1-2 m depth, a comparison by $\lambda$ (and then $\theta$ ) values - for all mixtures, using as reference material, $f_{s}$ and $s$ for fine and coarse mixtures, respectively, shows that: - the bentonite compounds in both groups had the lowest $\lambda$ values (Fig. 7a, b); 


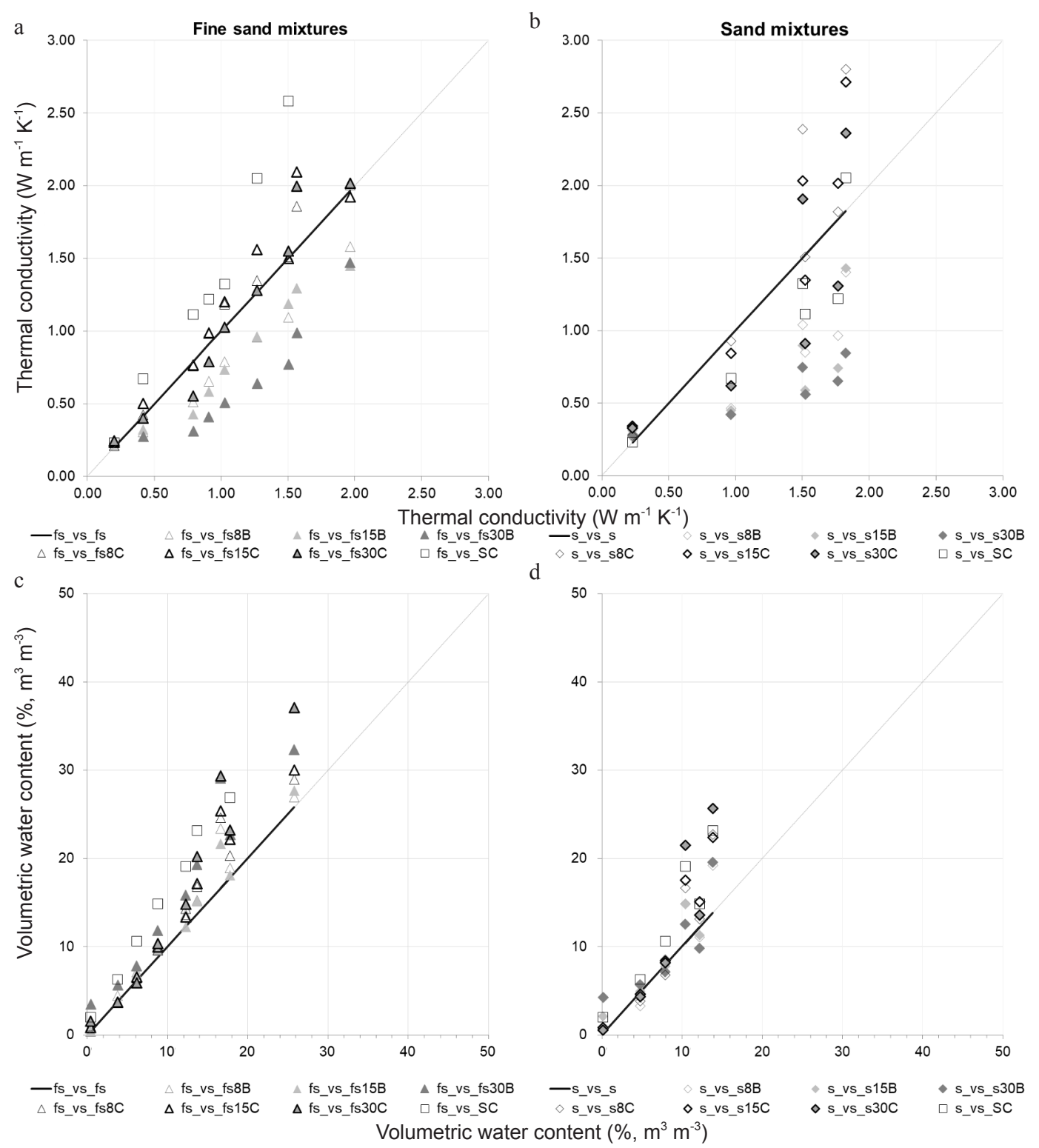

Fig. 7. Comparison by relative ratio of thermal conductivity (a-b) and of volumetric water content (c-d) values for all ITER mixtures measured inside the laboratory at a pressure step equal to $1000 \mathrm{~kg}$, where $1000 \mathrm{~kg}$ is representative of soil consolidation at approximately 1-2 m depth, $f s$ and $s$ have been considered as reference material for fine and coarse mixtures, respectively.

- in the fine textured materials (the clay powder compounds) showed a thermal behaviour equal to or slightly higher than that of $f s$ while $S C$, the natural soil, had the best heat transfer performance (Fig. 7a);

- in the coarse textured materials, the clay powder compounds and the loamy sand (SC) displayed a better thermal behaviour than did the bentonite mixtures; they showed also a great improvement of heat transfer capacity compared to the pure sand when the water content started to exceed the maximum amount hosted by the sand $\left(\approx 14 \%, \mathrm{~m}^{3} \mathrm{~m}^{-3}\right)$ (Fig. $\left.7 \mathrm{~b}-\mathrm{d}\right)$;

- the volumetric water content of the graded material (both $B$ or $C$ mixtures) was usually equal to or higher than that recorded in the pure material (both $s$ and $f s$ ) (Fig. 7c, d).
Hence, if a heat transfer ability equal to $1.5 \mathrm{~W} \mathrm{~m}^{-1} \mathrm{~K}^{-1}$ is required for a soil in the first meter of depth, it is possible to use $s$ or $f_{s}$ mixtures with a volumetric water content of about 8 or $18 \%, \mathrm{~m}^{3} \mathrm{~m}^{-3}$. However, these materials, especially the coarse sand, present a rapid increase / decrease of $\lambda$ values with small change in $\theta$ : a volumetric water content difference $(\Delta \theta)$ of only $3 \%, \mathrm{~m}^{3} \mathrm{~m}^{-3}$ in $s$ or $6 \%, \mathrm{~m}^{3} \mathrm{~m}^{-3}$ in $f_{s}$ reduces the thermal conductivity from 1.5 to $1.0 \mathrm{~W} \mathrm{~m}^{-1} \mathrm{~K}^{-1}$ (Fig. 8).

According to the laboratory results, the same decrease of $\lambda$ values requires a greater $\Delta \theta$ variation when other mixtures are taken into consideration (Table 3, Fig. 8). Thus, for fine textured materials, $f_{s} 8 B$ and $f_{s} 15 B$ showed $\Delta \theta$ variation above $10 \%, \mathrm{~m}^{3} \mathrm{~m}^{-3} ; f s 30 B-f s 8 C-f s 15 C$ - about $10 \%, \mathrm{~m}^{3} \mathrm{~m}^{-3}$; 

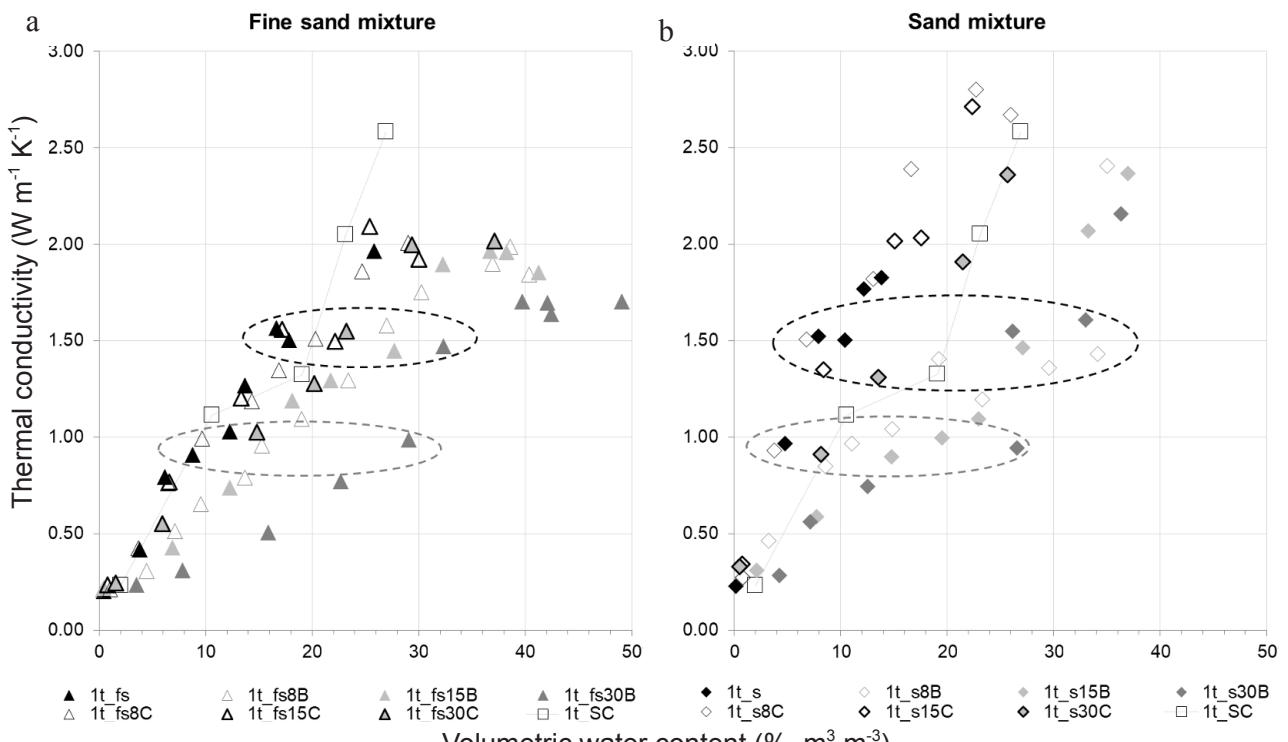

Volumetric water content $\left(\%, \mathrm{~m}^{3} \mathrm{~m}^{-3}\right)$

Fig. 8. Relationship between thermal conductivity and volumetric water content values for fine-grained (a) and coarse-grained (b) mixtures measured in laboratory at a pressure step equal to $+1000 \mathrm{~kg}$, where $1000 \mathrm{~kg}$ is representative of soil consolidation at approximately 1-2 m depth.

Table 3. Variation of volumetric water content $\left(\%, \mathrm{~m}^{3} \mathrm{~m}^{-3}\right)$ in the range $1.5-1.0 \mathrm{~W} \mathrm{~m}^{-1} \mathrm{~K}^{-1}$ for all the ITER mixtures tested, as determined in the laboratory by the combined analysis of data shown in Fig. 7

\begin{tabular}{|c|c|c|c|}
\hline \multirow{2}{*}{$\begin{array}{l}\text { ITER } \\
\text { material }\end{array}$} & \multicolumn{2}{|c|}{$\begin{array}{l}\text { Volumetric water content }(\theta) \\
\text { corresponding to }\end{array}$} & \multirow{2}{*}{$\Delta \theta$} \\
\hline & $1.5 \mathrm{~W} \mathrm{~m}^{-1} \mathrm{~K}^{-1}$ & $1.0 \mathrm{~W} \mathrm{~m}^{-1} \mathrm{~K}^{-}$ & \\
\hline$f_{s}$ & 18 & 12 & 6 \\
\hline$f_{S} 8 B$ & 27 & 15 & 12 \\
\hline$f_{s} 15 B$ & 28 & 17 & 11 \\
\hline$f_{s} 30 B$ & 39 & 29 & 10 \\
\hline$f_{s} 8 C$ & 20 & 10 & 10 \\
\hline$f_{s} 15 C$ & 19 & 9 & 10 \\
\hline$f_{s} 30 C$ & 23 & 15 & 8 \\
\hline$s$ & 8 & 5 & 3 \\
\hline$s 8 B$ & 20 & 12 & 8 \\
\hline$s 15 B$ & 2 & 19 & 8 \\
\hline$s 30 B$ & 27 & 20 & 7 \\
\hline$s 8 C$ & 8 & 4 & 4 \\
\hline$s 15 C$ & 10 & 4 & 6 \\
\hline$s 30 C$ & 17 & 9 & 8 \\
\hline$S C$ & 20 & 10 & 10 \\
\hline
\end{tabular}

$f_{s} 30 C$ - equal to $8 \%, \mathrm{~m}^{3} \mathrm{~m}^{-3}$. For coarse grained mixtures, with $\Delta \theta$ values of $8 \%, \mathrm{~m}^{3} \mathrm{~m}^{-3}$ belong to $s 8 B-s 15 B-s 30 C$ and below $8 \%, \mathrm{~m}^{3} \mathrm{~m}^{-3}$ to $s 30 B-s 15 C-s 8 C$. The loamy sand, representative of the natural material, covered an intermediate position between the two main groups already discussed $\left(\Delta \theta=10 \%, \mathrm{~m}^{3} \mathrm{~m}^{-3}\right)$.

Therefore, using $f_{s} 8 B-f_{s} 15 B$ or $f_{s} 8 C-f_{s} 15 C$, with an initial $\theta$ content of $27-28$ or $19-20 \%, \mathrm{~m}^{3} \mathrm{~m}^{-3}$, as backfilling material instead of $f s$, and of $s 8 B-s 15 B$ with an initial $\theta$ content of 20 and $27 \%, \mathrm{~m}^{3} \mathrm{~m}^{-3}$ instead of $s$, seem to be effective in order to preserve the thermal properties and guarantee a better VSG system performances by way of minimising the external effect that could dry out the shallow soil. For fine textured material, both a solution utilising 8 or $15 \%$ bentonite or clay powder can be considered, because the desired thermal conductivity values are obtained, on one hand, due to the ability to retain water and, on the other, because of the contribution of the quartz phase. The final decision about which TEBM to adopt is influenced also by the cost of the additive itself. For coarse textured material, options with 8 or $15 \%$ bentonite represent the best compromise between thermal properties, desired water content and mineralogical content. Finally, TEBMs with a $30 \%$ content of clay powder or bentonite must be disregarded as substitutes due: to the smaller heat transfer ability compared to the other mixtures, despite the increased moisture content recorded; and because of the greater costs and time required for their preparation.

\section{DISCUSSION}

In the framework of the ITER Project, the aim to create effective thermally enhanced backfilling materials using natural additives such as bentonite and clay powder on 
pure sand material (fine and coarse), in order to improve the ability to preserve thermal behaviour over time, led to the plan of extensive laboratory research. Several soil mixtures characterised by different grain size distribution were tested under different pressures, water content regimes and mineralogical contents - allowing the creation of a detailed database of physical-thermal properties variations in soil bodies.

The collected data constitute a valuable reference so as to support the modeling for very shallow geothermal applications and to validate heat and water transport models in unconsolidated material. Due to the specific methodological approach selected, the data can be directly related to in-situ field test measurements.

Herein, a rapid increase of $\lambda$ with an increase of $\theta$ and $\rho$ is observed for the coarse sand compounds. In such material, the highest achievable thermal conductivity obtained is strictly related to the kind of additive used ( $\lambda$ clay powder $>\lambda$ bentonite $>\lambda$ sand): the clay powder, characterized by a dominant quartz mineralogical phase, combined with volumetric water content around $30 \%, \mathrm{~m}^{3} \mathrm{~m}^{-3}$ and bulk density mainly between $1.6-1.8 \mathrm{~g} \mathrm{~cm}^{-3}$, allows an extension of $\lambda$ beyond $2.5 \mathrm{~W} \mathrm{~m}^{-1} \mathrm{~K}^{-1}$. In the fine sand mixtures, the increase of $\lambda$ with an increase of $\theta$ and $\rho$ is more gradual, and in all mixtures approaches equilibrium at circa $2.0 \mathrm{~W} \mathrm{~m}^{-1}$ $\mathrm{K}^{-1}$ : bentonite and clay powder mixtures reach similar $\lambda$, but are characterised by different $\rho$ and $\theta$ values ( $\rho$ bentonite mainly between $1.2-1.6 \mathrm{~g} \mathrm{~cm}^{-3} ; \rho$ clay powder mainly between $1.4-1.8 \mathrm{~g} \mathrm{~cm}^{-3} ; \theta$ bentonite $>40 \%, \mathrm{~m}^{3} \mathrm{~m}^{-3}, \theta$ clay powder $<40 \%, \%, \mathrm{~m}^{3} \mathrm{~m}^{-3}$ ).

Thus, such situations provide better (or worse) condition for optimising the performance of very shallow geothermal systems in the long term. In order to guarantee an optimal moisture content in shallow soils, according to the laboratory outputs, the most promising backfilling materials seem to be sand with 8 or $15 \%$ bentonite $(s 8 B, s 15 B)$ or fine sand with 8 or $15 \%$ bentonite or clay powder $\left(f_{s} 8 B, f_{s} 15 B, f_{s} 8 C\right.$, $f s 15 C$ ). Given that the bentonite compounds seem promising both for fine sand and sand mixtures and those with $15 \%$ bentonite present $\lambda$ values slightly higher than those with $8 \%$, the $f s 15 B$ and $s 15 B$ mixtures were selected, together with the plain sand $(s)$, fine sand $(f s)$ and loamy sand $(S C)$ tested in situ. Then, the experimental data measured in the test field could be compared with the database of thermallyenhanced backfilling material physical-thermal properties in order to better correlate the climatic factors that can influence the thermal properties of superficial soil bodies.

\section{CONCLUSIONS}

1. In general, to summarise, bulk density and moisture content affect both the thermal conductivity of soil bodies: on one hand, an increase of soil density for the same moisture content will lead to an increase of the thermal conductivity; on the other, for the same soil density, an increase in thermal conductivity is related to an increase of the moisture content. However, the measurements performed on 15 different unconsolidated sediment typologies confirm the dominant impact of water content on the thermal conductivity.

2. Sand grained mixtures show higher thermal conductivity and lower capacity to retain water than do fine textured material.

3. A gradual (or rapid) increase of thermal conductivity with volumetric water content in soils also implies a gradual (or rapid) dissipation of heat following water content reduction that is induced by environmental or anthropogenic factors.

\section{ACKNOWLEDGEMENTS}

Special thanks to REHAU Ag\&Co and Fischer Spezialbaustoffe Gmbh companies and their representatives - Ing. Mario Psyk and Mr Thomas Popp, for their collaboration and expertise. We thank Martin Potten, Hans Schwarz and Johannes Müller of the University of Erlangen for assisting in laboratory and field tests data acquisition, together with Dr. A. Galgaro and Dr. F. Zorzi of University of Padua (Italy) for their assistance with XRF analysis.

Competing interests: The authors declare that they have no conflict of interest.

\section{REFERENCES}

Abu-Hamdeh N.H., 2003. Thermal properties of soils as affected by density and water content. Biosys. Eng., 86(1), 97-102, doi:10.1016/S1537-5110(03)00112-0

Abu-Hamdeh N.H., Khdair A.I., and Reeder R.C., 2001. A comparison of two methods used to evaluate thermal conductivity for some soils. Int. J. Heat Mass Transfer, 44(5), 1073-1078, doi:10.1016/S0017-9310(00)00144-7

Abu-Hamdeh N.H. and Reeder R.C., 2000. Soil thermal conductivity effects of density, moisture, salt concentration, and organic matter. Soil Sci. Soc. Am. J., 64(4), 1285-1290, doi:10.2136/sssaj2000.6441285x

Ad-hoc-AG-Boden, 2005. Bodenkundliche Kartieranleitung, KA5. Schweizerbart'Sche Verlagsbuchhandlung, Hannover, Germany.

Alrtimi A., Rouainia M., and Haigh S., 2016. Thermal conductivity of a sandy soil. Applied Thermal Eng., 106, 551-560, doi:10.1016/j.applthermaleng.2016.06.012

Amundson R., Berhe A.A., Hopmans J.W., Olson C., Sztein A.E., and Sparks D.L., 2015. Soil and human security in the 21 st century. Science, 348 (6235), 1261071. doi:10.1126/ science. 1261071

Anbergen H., Frank J., Müller L., and Sass I., 2014. FreezeThaw-Cycles on Borehole Heat Exchanger Grouts: Impact on the Hydraulic Properties. Geotechnical Testing J., 37, 20130072, doi:10.1520/GTJ20130072

Anbergen H., Rühaak W., Frank J., and Sass I., 2015. Numerical simulation of a freeze-thaw testing procedure for borehole heat exchanger grouts. Canadian Geotechnical J., 52, 1087-1100, doi:10.1139/cgj-2014-0177.

ASTM (American Society for Testing and Materials International), 2008. Standard test method for determination of thermal 
conductivity of soil and soft rock by thermal needle probe procedure. D5334-08. West Conshohocken, PA: ASTM International; 8, doi:10.1520/D5334-08

Balghouthi M., Kooli S., Farhat A., Daghari H., and Belghith A., 2005. Experimental investigation of thermal and moisture behaviors of wet and dry soils with buried capillary heating system. Solar Energy, 79(6), 669-681, doi:10.1016/j. solener.2005.06.011

Bayerischen Geologischen Landesamt, 1971. Geologischen Karte von Bayern 1:25 000, Blatt Nr. 6431 Herzogenaurach (Geological Map of Bavaria 1:25 000, Sheet Nr. 6431 Herzogenaurach).

Bertermann D., Bialas C., Morper-Busch L., Klug H., Rohn J., Stollhofen M. P., Psyk M., Jaudin F., Maragna C., Einarssom G.M., Vikingsson S., Orosz L., Jordan G., Vîidea A.M., Lewis M., Lawley R.S., Roinevirta S., Declercq P.Y., Petitclerc E., Zacherl A., Arvanitas A.A., and Stefouli M., 2013. ThermoMap - an open-source web mapping application for illustrating the very shallow geothermal potential in Europe and selected case study areas. In: European Geothermal Congress, Pisa, 1-7.

Bertermann D., Klug H., and Morper-Busch L., 2015. A panEuropean planning basis for estimating the very shallow geothermal energy potentials. Renewable Energy, 75, 335347, doi:10.1016/j.renene.2014.09.03

Bertermann D., Klug H., Morper-Busch L., and Bialas C., 2014. Modelling vSGPs (very shallow geothermal potentials) in selected CSAs (case study areas). Energy, 71, 226-244, doi:10.1016/j.energy.2014.04.054

Bertermann D. and Schwarz H., 2017. Laboratory device to analyse the impact of soil properties on electrical and thermal conductivity. Int. Agrophys., 31(2), 157-166, doi:10.1515/intag-2016-0048

Bristow K.L., 1998. Measurement of thermal properties and water content of unsaturated sandy soil using dual-probe heat-pulse probes. Agricultural Forest Meteorol., 89(2), 75-84.

Chesworth W., 2008. Encyclopedia of soil science. Encyclopedia of earth sciences series. Springer, Dordrecht, Netherlands.

Chong C.S.A., Gan G., Verhoef A., Garcia R.G., and Vidale P.L., 2013. Simulation of thermal performance of horizontal slinky-loop heat exchangers for ground source heat pumps. Applied Energy, 104, 603-610, doi:10.1016/j. apenergy.2012.11.069

Choo J., Kim Y.J., Lee J.H., Yun T.S., Lee J., and Kim Y.S., 2013. Stress-induced evolution of anisotropic thermal conductivity of dry granular materials. Acta Geotechnica, 8(1), 91-106, doi:10.1007/s11440-012-0174-7

Clauser C., 2011a. Thermal storage and transport properties of rocks, I: heat capacity and latent heat. In: Encyclopedia of Solid Earth Geophysics (Ed. H.K. Gupta), Springer Press, Dordrecht, Netherlands, doi: 10.1007/978-90-481-87027 238

Clauser C., 2011b. Thermal storage and transport properties of rocks, II: thermal conductivity and diffusivity. In: Encyclopedia of Solid Earth Geophysics (Ed. H.K. Gupta), Springer Press, Dordrecht, Netherlands, doi: 10.1007/ 978-90-481-8702-7_67

Dalla Santa G., Galgaro A., Tateo F., and Cola S., 2016. Modified compressibility of cohesive sediments induced by thermal anomalies due to a borehole heat exchanger. Engineering Geology, 202, 143-152, doi:10.1016/j. enggeo.2016.01.011

DeVries D.A., 1963. Thermal properties of soils. In Physics of Plant Environment (Ed. W.R. van Wijk), Wiley: New York.

DIN 18121-1, 1998. Soil, Investigation and Testing: Water Content Part 1. Determination by Drying in Oven, German Standard DIN, Berlin (Deutsches Institut für Normung).

DIN 52102-02, 2006. Test methods for aggregates - Determination of dry bulk density by the cylinder method and calculation of the ratio of density, German Standard DIN, Berlin (Deutsches Institut für Normung).

DIN 18123, 2011. Soil, Investigation and Testing: Determination of grain size distribution, German Standard DIN, Berlin (Deutsches Institut für Normung).

Di Sipio E. and Bertermann D., 2017a. Influence of Different Moisture and Load Conditions on Heat Transfer within Soils in Very Shallow Geothermal Application: An Overview of ITER Project. In: Proc., 42nd Workshop on Geothermal Reservoir Engineering, Stanford University, Stanford, California, February 13-15, 1345-1353, SGP-TR212GC 2016.

Di Sipio E. and Bertermann D., 2017b. Factors Influencing the Thermal Efficiency of Horizontal Ground Heat Exchangers. Energies, 10(11), 1897, doi:10.3390/en10111897

Di Sipio E., Bertermann D., Psyk M., and Popp T., 2016. Improving Thermal Efficiency of horizontal ground heat exchangers. In: EGC 2016- European Geothermal Congress Proceedings, Strasbourg (France), 19-23.09.2016, EGC2016-T-EP-72, 1-5.

Dong Y., McCartney J.S., and Lu N., 2015. Critical review of thermal conductivity models for unsaturated soils. Geotechnical Geological Eng., 33(2), 207-221, doi:10.1007/ s10706-015-9843-2.

Drefke C., Schedel M., Stegner J., Balzer C., Hinrichsen V., and Sass I., 2017. Measurement method of thermal properties of cementitious bedding materials and unsaturated soils: Hydraulic influence on thermal parameters. Geotechnical Testing J., 40(1), 160-170, doi:10.1520/ GTJ20160027

Farouki O.T., 1981. Thermal properties of soils (No. CRRELMONO-81-1). Cold Regions Research and Engineering Lab Hanover Nh.

Gonzalez R.G., Verhoef A., Vidale P.L., Main B., Gan G., and Wu Y., 2012. Interactions between the physical soil environment and a horizontal ground coupled heat pump, for a domestic site in the UK. Renewable Energy, 44, 141-153, doi: 10.1016/j.renene.2012.01.080

Hillier S., 2000. Accurate quantitative analysis of clay and other minerals in sandstones by XRD: comparison of a Rietveld and a reference intensity ratio (RIR) method and the importance of sample preparation. Clay Minerals, 35(1), 291-302, doi:10.1180/000985500546666

Hinkel K.M., Paetzold R.F., Nelson F.E., and Bockheim J.G., 2001. Patterns of soil temperature and moisture in the active layer and upper permafrost at Barrow, Alaska: 1993-1999. Global and Planetary Change 29, 293-309.

Hiraiwa Y. and Kasubuchi T., 2000. Temperature dependence of thermal conductivity of soil over a wide range of temperature $\left(5-75^{\circ} \mathrm{C}\right)$. European J. Soil Sci., 51.2, 211-218. 
IMKO Micromodultechnik GmbH, 2015. TRIME-PICO 64/32 manual, IMKO Micromodultechnik GmbH, Ettlingen, Germany, 1-52.

Kömle N.I., Bing H., Feng W.J., Wawrzaszek R., Hütte, E.S., He P., Marczewski W., Dabrowski B., Schröer K., and Spohn T., 2007. Thermal conductivity measurements of road construction materials in frozen and unfrozen state. Acta Geotechnica, 2(2), 127-138, doi: 0.1007/ s11440-007-0032-1

Kukkonen I. and Lindberg A., 1998. Thermal properties of rocks at the investigation sites: measured and calculated thermal conductivity, specific heat capacity and thermal diffusivity. Work. Rep. 98-09e, Posiva Oy, Helsinky.

Leong W.H., Tarnawski V.R., and Aittomäki A., 1998. Effect of soil type and moisture content on ground heat pump performance: Effet du type et de l'humidité du sol sur la performance des pompes à chaleur à capteurs enterrés. Int. J. Refrigeration, 21(8), 595-606.

Lu S., Ren T., Gong Y., and Horton R., 2007. An improved model for predicting soil thermal conductivity from water content at room temperature. Soil Sci. Soc. America J., 71(1), 8-14, doi:10.2136/sssaj2006.0041

Luo J., Rohn J., Xiang W., Bertermann D., and Blum P., 2016. A review of ground investigations for ground source heat pump (GSHP) systems. Energy Buildings, 117, 160-175, doi:10.1016/j.enbuild.2016.02.038.

Moya R.E.S., Prata A.T., and Neto J.C., 1999. Experimental analysis of unsteady heat and moisture transfer around a heated cylinder buried into a porous medium. Int. J. Heat Mass Transfer, 42(12), 2187-2198.

Naylor S., Ellett K.M., and Gustin A.R., 2015. Spatiotemporal variability of ground thermal properties in glacial sediments and implications for horizontal ground heat exchanger design. Renewable Energy, 81, 21-30, doi:10.1016/j.renene.2015.03.006.

Nikolaev I.V., Leong W.H., and Rosen M.A., 2013. Experimental investigation of soil thermal conductivity over a wide temperature range. Int. J. Thermophysics, 34(6), 1110-1129, doi:0.1007/s10765-013-1456-5.

Ochsner T.E., Horton R., and Ren T., 2001. A new perspective on soil thermal properties. Soil Sci. Soc. American J., 65(6), 1641-1647.

Rietveld H., 1969. A profile refinement method for nuclear and magnetic structures. J. Appl. Crystallography, 2(2), 65-71.

Salomone L.A., Kovacs W.D., and Kusuda T., 1984. Thermal performance of fine-grained soils. J. Geotechnical Eng., 110(3), 359-374.

Saxton K.E. and Rawls W.J., 2006. Soil water characteristic estimates by texture and organic matter for hydrologic solutions. Soil Sci. Soc. America J., 70(5), 1569-1578, doi:10.2136/sssaj2005.0117

Schön J.H., 2011. Physical Properties of Rocks. A workbook. In: Handbook of Petroleum Exploration and Production (Ed. J. Cubitt), Elsevier B.V., Amsterdam, The Netherlands.

Smits K.M., Sakaki T., Limsuwat A., and Illangasekare T.H., 2010. Thermal conductivity of sands under varying moisture and porosity in drainage-wetting cycles. Vadose Zone J., 9(1), 172-180, doi:10.2136/vzj2009.0095

Song W.K., Cui Y.J., Tang A.M., Ding W.Q., and Tran T.D., 2014. Experimental study on water evaporation from sand using environmental chamber. Canadian Geotechnical J., 51(2), 115-128, doi:10.1139/cgj-2013-0155
Susha Lekshmi S.U., Singh D.N., and Baghini M.S., 2014. A critical review of soil moisture measurement. Measurement, 54, 92-105.

Syvitski J.P., 2007. Principles, methods and application of particle size analysis, Cambridge University Press.

Tarnawski V.R. and Gori F., 2002. Enhancement of the cubic cell soil thermal conductivity model. Int. J. Energy Res., 26(2), 143-157, doi:10.1002/er.772

Tarnawski V.R. and Leong W.H., 2000. Thermal conductivity of soils at very low moisture content and moderate temperatures. Transport in Porous Media, 41(2), 137-14.

Tarnawski V.R., McCombie M.L., Momose T., Sakaguchi I., and Leong W.H., 2013. Thermal conductivity of standard sands. Part III. Full range of saturation. Int. J. Thermophysics, 34(6), 1130-1147, doi:10.1007/s10765-013-1455-6

Tarnawski V.R., Momose T., and Leong W.H., 2011. Thermal conductivity of standard sands II. Saturated conditions. Int. J. Thermophysics, 32(5), 984-1005, doi:10.1007/ s10765011-0975-1

Tarnawski V.R., Momose T., Leong W.H., Bovesecchi G., and Coppa P., 2009. Thermal conductivity of standard sands. Part I. Dry-state conditions. Int. J. Thermophysics, 30(3), 949-968, doi:10.1007/s10765-009-0596-0

Terzaghi K. and Peck R.B., 1948. Soil mechanics in engineering practice. John Wiley and Sons, New York, USA

Tien Y.M., Chu C.A., Wu P.L., Chuang W.S., and Chung Y.J., 2010. Improved measurement and a predictive model for thermal conductivity of sand-bentonite mixtures. J. GeoEng., 5(2), 51-60.

USDA United States Department of Agriculture, 1987. Soil Mechanics Level 1 - Module 3, USDA textural soil classification, Study Guide, Soil Conservation Service USDA

USDA United States Department of Agriculture, 2012. Engineering Classification of Earth Materials, Chapter 3, in Part 631 National Engineering Handbook, United States Department of Agriculture (USDA) Natural Resources Conservation Service (NRCS), 210-VI-NEH, Amend. 55.

Usowicz B., Kossowski J., and Baranowski P., 1996. Spatial variability of soil thermal properties in cultivated fields. Soil Till. Res., 39(1-2), 85-100.

Venkatramaiah C., 2014. Geotechnical Engineering. New Age International Pvt Ltd Publishers, New Dehli, India.

Webb P.A., 2004. The perseverance of the SediGraph method of particle sizing, Micromeritics Instrument Corporation.

Wu R., Tinjum J.M., and Likos W.J., 2015. Coupled Thermal Conductivity Dryout Curve and Soil-Water Characteristic Curve in Modeling of Shallow Horizontal Geothermal Ground Loops. Geotechnical and Geological Engineering, 33(2), 193-205, doi:10.1007/s10706-014-9811-2

Yun T.S. and Santamarina J.C., 2008. Fundamental study of thermal conduction in dry soils. Granular Matter, 10(3), 197-207, doi:10.1007/s10035-007-0051-5

Zhang N., Yu X., Pradhan A., and Puppala A.J., 2016. A new generalized soil thermal conductivity model for sand-kaolin clay mixtures using thermo-time domain reflectometry probe test. Acta Geotechnica, 1-14, doi:10.1007/s11440016-0506-0.

Zhang T., Cai G., Liu S., and Puppala A.J., 2017. Investigation on thermal characteristics and prediction models of soils. Int. J. Heat Mass Transfer, 106, 1074-1086, doi:10.1016/j. ijheatmasstransfer.2016.10.084 